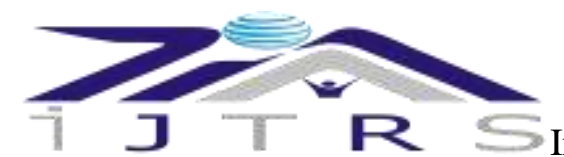

\title{
MEDICAL TOURISM IN INDIA: STRENGTHS AND WEAKNESSES
}

\author{
Dr. Priya .K \\ E-Mail Id: priyakrishan17@gmail.com \\ Associate Professor \& Head, Department of Commerce, Vivekanandha College of Arts \& Sciences for \\ Women (Autonomous), Elayampalayam,Tiruchengode, Namakkal (Dt)
}

\begin{abstract}
Medical tourism is rapidly growing in India. It is expected to do billion dollar business. Indian healthcare system is traditionally strong and Indian people are good enough in the medical profession. Medical tourism industry provides lot of foreign exchange to the nation. It is expected that medical tourism will going to play an important role in the Indian economy. This industry has its own merits and demerits. This paper is an attempt to give an overview on the Indian Medical Tourism industry. Its strengths and weaknesses are elaborately discussed.

Keywords: Medical tourism in India, Role of healthcare in Indian Economy

\section{INTRODUCTION}

Medical Tourism is important and fastest growing field. Lots of expectations are there on this field in India. Lot of foreigners visiting India for their medical treatment is the reason for the development of medical tourism in India. Indian healthcare system and scope for the development pave way for the improvement of medical tourism.
\end{abstract}

\section{MEDICAL TOURISM}

Medical Tourism can be generally defined as the movement of people for the purpose of getting cost effective personal health care in association with the tourism industry for patients who are in need of surgical health care and other forms of dedicated treatment.

Medical tourism is basically classified into three types. First one is, outbound. In this type of tourism, the patients travel from home country to a foreign country. Secondly, Inbound, where the patient travelling to home country from the foreign country. Third type is intrabound or domestic, that patients are travelling within the country for medical treatment.

Medical tourism is a new form of a niche tourism market which has been rapidly growing in the recent years. The term medical tourism is the act of traveling to other countries to obtain medical, dental and surgical care. Medical tourism is the attempt to attract tourists by deliberately promoting its health-care services and facilities, in addition to its regular tourist amenities. This includes getting indigenous and alternative medical services, and any other form of tourism undertaken with the purpose of addressing a health concern. It is a popular mass culture where people travel to overseas countries to obtain healthcare services and facilities such as medical, dental and surgical care whilst having the opportunity to visit the tourist spots of that country. Medical tourism is a travel which is systematically planned to maintain one's physical and mental health condition.

Normally, the majority of medical tourists come from the industrialized countries of the world especially Europe, the UK, Middle East, Japan, U.S. and Canada where the cost of medical treatment is very expensive and there are often long waiting times for treatments. Other than India, countries that are currently promoting medical tourism are Thailand, Malaysia, Singapore, South Korea Bolivia, Brazil, Belgium, Cuba, Costa Rica, Hungary, and Jordan. Private sector development in emerging economies - such as India, Thailand, Singapore, and certain Latin American nations - attracts foreign patients for relatively cheaper care: the uninsured, the underinsured, or those who prefer not to wait for treatment under a national health insurance system.

An official website says that global medical tourism industry is a $\$ 45.5-\$ 72$ billion industry and approximately twelve million patients travel abroad. They are spending an average of $\$ 3,800-\$ 6,000$ per visit (including medicallyrelated costs, visa and local transport, inpatient stay and accommodations).

\section{MEDICAL TOURISM IN INDIA}

The industry is experiencing more than $10 \%$ growth in India and various estimates peg the size of the Indian medical tourism industry at $\$ 3$ billion in 2015 , which is expected to grow to $\$ 7-8$ billion by 2020 . The top global medical tourism destinations include Costa Rica, India, Israel, Malaysia, Mexico, Singapore, South Korea, Taiwan, Thailand, Turkey and the United States. Around 600,000 medical tourists travelled to India in 2015. Indian healthcare industry caters to about 1.25 billion Indians and people coming from Africa, Middle-East and SAARC countries. India caters to the healthcare needs of a population of almost 2 billion people globally. India gets high value patients for surgeries in key specialties such as organ transplants (liver, heart \& lung and kidney), neurosurgeries, cardiothoracic surgeries, oncology, orthopaedics and many others. 


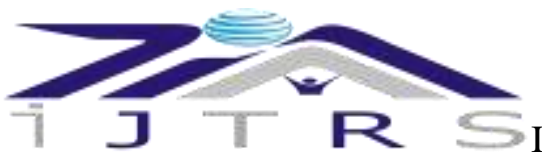

International Journal of Technical Research \& Science

AIIMs (a public - sector hospital owned by the central government) The Apollo Hospitals, Escorts Hospital, Fortis Hospitals, Breach Candy, Hinduja, Mumbai's Asian Heart Institute, Arvind Eye Hospitals, Manipal Hospitals, Mallya Hospital, Shankara Nethralaya etc are the major service providers in Indian medical tourism. Delhi, Chennai, Bangalore and Mumbai cater to the maximum number of health tourists and are fast emerging as medical tourism hubs. Nowadays medical tourism in India includes advanced and life savings health care services like open transplants, cardio vascular surgery, eye treatment, knee/hip different cosmetic surgeries and alternate systems of medicine. Also leisure aspect medical traveling/wellness tourism may be included on such medical travel trips. India provides a variety of medical services to overseas patients.

The main reasons for the growing popularity in medical tourism in India are: (a) the long waiting lists in the developed countries, (b) the low cost of medical treatments in India than the other developed countries. In India, complicated surgical procedures are being done at one-tenth of the cost as compared to the procedures in the developed countries, (c) the affordable international air fares and favorable exchange rates, (d) the Internet; with the development of communications, new companies have emerged who acts as middlemen between international patients and hospital networks, giving patients easy access to information, prices and option, (e) the state-of-art technology, specialist doctors, nurses and para- medical staffs that has been adopted by the big hospitals and diagnostics centers in India. In India, the medical education system also caters to the ever increasing demand for the delivery of the quality health care services all over the country.

\section{A COST COMPARISON}

The cost of medical treatment is looking cheaper in India. The cost of Heart bypass is $\$ 10000$ in India (\$130000 in US, \$11000 in Thailand and \$18500 in Singapore). The cost heart volve replacement is \$ 9000 in India (\$160000 in US, $\$ 10000$ in Thailand and $\$ 12500$ in Singapore). The medical expense for Angioplasty is $\$ 11,000$ in India, $\$ 57,000$ in US, $\$ 13,000$ in Thailand and \$13,000 in Singapore. Hip replacement cost is \$43,000 in US, \$ 9,000 in India and 12,000 in Thailand and Singapore.

Quality care, relatively cheaper services compared to the west, package deals and cheap services from the tourism and hospitality sectors are the biggest attraction of medical tourism in India. The price differentials of various procedures for Singapore, Thailand and India with the USA reveal the economic advantage offered to interested patients by India.

\section{MEDICAL TOURISM IN INDIA: PROSPECTS AND PROBLEMS}

\section{Indian medical tourism has the following features:}

\subsection{Quality of Service}

Indian healthcare sector has international quality of service. The big hospitals have a standardized machines and talented doctors. The hospitals in the metro cities are playing major role in the medical tourism. They are providing best quality of service.

\subsection{Affordable Cost}

The cost of medical treatment is very low in India compared to other nations who provide world class medical service. Hence, India is the best destination for the medical tourist who seeks for better treatment with lower cost.

\subsection{Suit for All}

Indian Healthcare sector provides services for all kind of people. There are lot of classes of service economically and type of medical treatment (Siddha, Ayurveda, Allopathic, Yoga and Acupuncture, etc., The medical tourism is suitable for all economical and diseased patients.

\subsection{Scope for Increase in Demand}

There is lot of scope for medical tourism in India due to the healthy environment for the industry and poor lifestyle of the people. The fast food culture and stressed working environment pave the way for need of medical service. India is looking better in providing quality of service and economical viability. Old aged people are also need more medical support.

\subsection{Availability of Advanced Machines}

In India, big hospitals are replacing advanced machines for their better services. They are well versed in their specialized treatment and able to import the equipments immediately from anywhere in the world. India hospitals are at the international standard.

\subsection{Excellent Professionals}




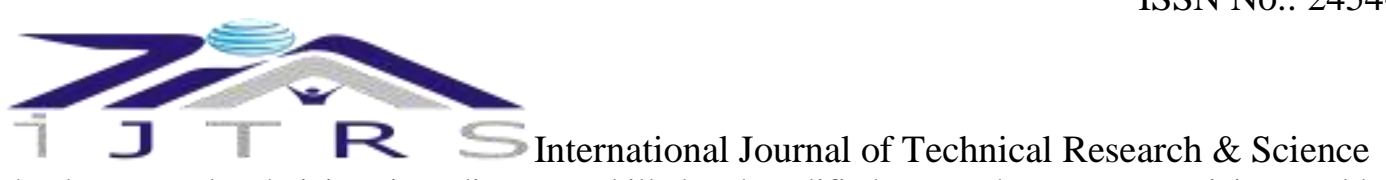

The doctors and technicians in India are so skilled and qualified. Many doctors are servicing worldwide. The doctors in many fields have been specialized in many field. Indians are also strong in the research and development.

\subsection{Lack of Service in Foreign Countries}

There is another scope for development in Indian Medical tourism due to lack or shortage of medical service in the western countries. Hence, Indian healthcare industry is the heaven for the patients from abroad.

These are problems related to Indian medical tourism:

\subsubsection{Lack of Other Services}

In the Indian scenario, it is very difficult to coordinate other services by the foreign patients like airways, hotels and hospitals. The services are developing now in the technological world. It will take sometimes to improve. They need a support from India to coordinate everything.

\subsubsection{No Strict Regulation and Proper Support}

The support from the Indian government in this regard is very lacking. The government doesn't have any specific policy and regulation for the safety of the patients who are coming to India for the medical treatment. There is no monitoring body and strict regulation to control and follow the service given to the foreigners.

\subsubsection{Lot of Diversity in Service and Pricing}

It is the character of Indian system that varieties of medical methods, types and cost. It is varying according to the type, method and place. The foreign medical traveler could not understand the system and get confused with the environment.

\subsubsection{No Proper Standardized the Services}

Big hospitals in India are having ISO and other certification for their services. But most of the hospitals have not accreditated their service and organization in India. It will give poor image about the Indian Medical system.

\subsubsection{Opinion about the Country}

When compared to the western countries, India opined as unhygienic. The low cleanliness and more dirtiness environment bring bad image about the country. This general opinion destructs to attract the foreign visitors. It should be changed through remedial actions.

\subsubsection{Inadequate Investment in Health Care Industry}

The healthcare industry in India does not have an adequate investment compared to other competitive nations. According to the size of the size of the industry, the investment is not enough for further development. Only few corporate can have the investment but in all hospitals.

\subsubsection{Strong Competition from the Other Nations}

Thailand, Singapore and Malaysia are strong competitors to India in the medical tourism industry. Hence, India should be prepared for it in terms of quality and cost of the service. In future, it will be difficult to face the competition due to economical conditions.

\subsubsection{Financial Settlement}

For the convenient of facing medical expenses, medical insurance policies are taken. Particularly, this awareness is very high in the western countries. The overseas medical cover is suitable to India. In this aspect, the visitors will think about the cost of the treatment. It is a big flow in terms of financial conditions.

\section{CONCLUSION}

The medical tourism is rapidly growing in India. It will contribute lot to the economy of the country through earning more foreign exchange. The government and the stakeholders of the healthcare sector are focusing on attracting the patients from the abroad. There are some challenges to the industry as it competes internationally. The improvement and sustain quality and better government policy to support the industry and ease the formalities related to visa and other formalities should be done for the betterment of healthcare industry.

\section{REFERENCE}

[1] http://www.docstoc.com/docs/12163631/MEDICAL-TOURISM/P/36

[2] www.patientsbeyondborders.com

[3] Carrera, P.M. \& Bridges J.F.P (2006), "Globalisation and Healthcare : Understanding Health and Medical tourism”, Expert review of Pharmacoeconomics and Outcomes Research , 6(4), pp.447- 454. 
I $\rightleftharpoons$ International Journal of Technical Research \& Science

[4] Horowitz, M. \& Rosenweig, J. (2007), "Medical Tourism-health care in the global Economy", The Physician Executive, pp. 24-30.

[5] Suman Kumar Dawn and swati pal (2011), "Medical Tourism in India: Issues, Opportunities and Designing Strategies for Growth and Development", ZENITH International Journal of Multidisciplinary Research, 1(3), pp.185-202. 